\title{
Soot Surface Reactions in High-Temperature Laminar Diffusion Flames
}

\author{
A. M. El-Leathy, ${ }^{*}$ C. H. Kim ${ }^{\dagger}$ and G. M. Faeth ${ }^{\ddagger}$ \\ University of Michigan, Ann Arbor, Michigan 48109 \\ and \\ F. $\mathrm{Xu}^{\S}$ \\ University of Central Florida, Orlando, Florida 32816
}

\begin{abstract}
The structure and the soot surface growth and surface oxidation properties of round laminar jet diffusion flames were studied experimentally. Measurements were made along the axes of acetylene/argon-fueled flames burning at atmospheric pressure in coflowing oxygen/argon mixtures to provide higher temperature soot-containing regions $(2000-2350 \mathrm{~K})$ than were considered during earlier work. The measurements yielded soot surface growth and surface oxidation rates as well as the flame properties that are thought to control these rates. The present measurements of soot surface growth rates (corrected for soot surface oxidation) were consistent with earlier measurements in laminar premixed and diffusion flames having lower temperatures and exhibited good agreement with existing hydrogen-abstraction/carbon-addition soot surface growth rate mechanisms in the literature with steric factors of these mechanisms having values on the order of unity, as anticipated. Similarly, the present measurements of soot surface oxidation rates (corrected for soot surface growth) were consistent with earlier measurements in laminar premixed and diffusion flames having lower temperatures and exhibited good agreement with existing $\mathrm{OH}$ soot surface oxidation mechanisms in the literature, with a collision efficiency for $\mathrm{OH}$ of 0.13 , in good agreement with past work, and supplemented to only a minor degree by direct soot surface oxidation by $\mathrm{O}_{2}$.
\end{abstract}

\section{Nomenclature}

$C_{i}=$ mass of carbon oxidized per mole of species $i$ reacted, $\mathrm{kg} \mathrm{kgmol}^{-1}$

$d=$ fuel port exit diameter, $\mathrm{m}$

$d_{p}=$ mean primary soot particle diameter, $\mathrm{m}$

$F r=$ burner exit Froude number, $u_{0}^{2} /(g d)$

$f_{s}=$ soot volume fraction

$g=$ acceleration of gravity, $\mathrm{m} \mathrm{s}^{-2}$

$[i]=$ molar concentration of species $i, \mathrm{kgmol} \mathrm{m}^{-3}$

$k_{H}=$ constant in simplified soot surface growth rate formula, $\mathrm{kg} \mathrm{m}^{4} \mathrm{kgmol}^{-2} \mathrm{~s}^{-1}$

$M_{i}=$ molecular weight of species $i, \mathrm{~kg} \mathrm{kgmol}^{-1}$

$R e=$ burner exit Reynolds number, $u_{0} d / v_{0}$

$R_{u}=$ universal gas constant, $\mathrm{J} \mathrm{kgmol}^{-1} \mathrm{~K}^{-1}$

$T=$ temperature, $\mathrm{K}$

$t \quad=$ time, $\mathrm{s}$

$u=$ streamwise velocity, $\mathrm{m} \mathrm{s}^{-1}$

$\bar{v}_{i}=$ mean molecular velocity of species $i, \mathrm{~m} \mathrm{~s}^{-1}$

$w_{g}=$ soot surface growth rate, $\mathrm{kg} \mathrm{m}^{-2} \mathrm{~s}^{-1}$

$w_{\mathrm{ox}}=$ soot surface oxidation rate, $\mathrm{kg} \mathrm{m}^{-2} \mathrm{~s}^{-1}$

$\alpha_{i}=$ empirical (steric) factors in the hydrogen abstraction/carbon addition (HACA) soot surface growth rate formulas

$=$ collision efficiency of species $i$

$=$ kinematic viscosity, $\mathrm{m}^{2} \mathrm{~s}^{-1}$

$=$ fuel-equivalence ratio

Received 18 June 2003; revision received 5 December 2003; accepted for publication 11 December 2003. Copyright (C) 2004 by the authors. Published by the American Institute of Aeronautics and Astronautics, Inc., with permission. Copies of this paper may be made for personal or internal use, on condition that the copier pay the $\$ 10.00$ per-copy fee to the Copyright Clearance Center, Inc., 222 Rosewood Drive, Danvers, MA 01923; include the code 0001-1452/04 \$10.00 in correspondence with the CCC.

* Research Associate, Department of Aerospace Engineering.

†raduate Student Research Assistant, Department of Aerospace Engineering.

A. B. Modine Professor, Department of Aerospace Engineering. Fellow AIAA.

${ }^{\S}$ Assistant Professor, Department of Mechanical, Materials and Aerospace Engineering.

\begin{abstract}
Subscripts
$\mathrm{CH}=$ HACA soot surface growth mechanism of Colket and Hall ${ }^{11}$

eq $=$ property for thermodynamic equilibrium conditions

$\mathrm{FW}=$ HACA soot surface growth mechanism of Frenklach and Wang ${ }^{12,13}$ and Kazakov et al. ${ }^{14}$

$0=$ burner exit condition
\end{abstract}

\section{Introduction}

Q OOT processes within flames fueled with hydrocarbons are $\checkmark$ important because they affect the durability and performance of propulsion systems, the hazards of unwanted fires, the pollutant and particulate emissions of combustion processes, and the potential for computational combustion. Motivated by these observations, studies of the structure and soot surface reaction properties of laminar flames that have temperatures within the sootcontaining region smaller than $2000 \mathrm{~K}$ have been undertaken for a variety of flame types: ethylene/air premixed flames at atmospheric pressure, ${ }^{1}$ methane/oxygen premixed flames at atmospheric pressure, ${ }^{2,3}$ acetylene/air nonpremixed (diffusion) flames at pressures of $0.1-1.0 \mathrm{~atm},{ }^{4-7}$ and various hydrocarbon/air diffusion flames at atmospheric pressure. ${ }^{8-10}$ These studies resolved a number of features of soot surface reactions in laminar flame environments: soot surface growth rate properties were essentially independent of fuel type and of whether the soot-containing region was within a premixed or a diffusion flame; soot surface growth rates were well represented by the hydrogen-abstraction/carbon-addition (HACA) mechanisms of Colket and Hall, ${ }^{11}$ Frenklach and Wang, ${ }^{12,13}$ and Kazakov et al., ${ }^{14}$ and soot surface oxidation rates were dominated by reaction with $\mathrm{OH}$, as proposed by Neoh et al., ${ }^{15-17}$ with a small correction due to direct soot surface oxidation by $\mathrm{O}_{2}$ taken from Nagle and Strickland-Constable. ${ }^{18}$

Given this status, the present investigation sought to consider soot surface reactions at temperatures (2000-2350 K) higher than considered before. Concern about effects of larger temperatures comes from the tendency of soot surfaces to become less effective for promoting soot surface growth as surface temperatures increase, an effect that the HACA soot surface growth rate mechanisms of Colket and Hall, ${ }^{11}$ Frenklach and Wang, ${ }^{12,13}$ and Kazakov et al. ${ }^{14}$ seek to 
capture in different ways. The studies of Refs. 1-10 have shown that effects of fuel type (for several hydrocarbons, e.g., methane, acetylene, ethylene, propylene, propane, and benzene), flame type (premixed or diffusion flame), and pressure (for the range 0.1-1.0 atm) were handled reasonably well by the fundamental HACA soot surface growth rate mechanisms of Colket and Hall, ${ }^{11}$ Frenklach and Wang, ${ }^{12,13}$ and Kazakov et al. ${ }^{14}$ and by the $\mathrm{OH} / \mathrm{O}_{2}$ soot surface oxidation mechanisms of Neoh et al. ${ }^{15-17}$ and Nagle and StricklandConstable. ${ }^{18}$ As a result, present test conditions were limited to acetylene/argon-fueled laminar jet diffusion flames at atmospheric pressure, burning in coflowing oxygen/argon mixtures (which provides higher temperatures in the soot-containing region than earlier flames burning in air because argon as the diluent has a smaller specific heat than nitrogen as the diluent in air).

To summarize, the specific objectives of the present study were as follows: 1) to measure the flame structure (temperatures, stable and radical species concentrations, and velocities) and soot properties (soot volume fractions and primary soot particle diameters) within the soot-containing region of acetylene/argon-fueled laminar jet diffusion flames burning in coflowing oxygen/argon mixtures at atmospheric pressure; 2) to exploit both the new measurements and existing measurements in premixed flames ${ }^{1-3}$ and in diffusion flames, ${ }^{6,7,9,10}$ to evaluate and correlate the HACA soot surface growth mechanisms of Colket and Hall, ${ }^{11}$ Frenklach and Wang, ${ }^{12,13}$ and Kazakov et al. ${ }^{14}$; and 3) to exploit both the new measurements and existing measurements in premixed flames ${ }^{15}$ and in diffusion flames, ${ }^{6}$ to evaluate the $\mathrm{OH} / \mathrm{O}_{2}$ mechanisms of soot surface oxidation of Neoh et al. ${ }^{15}$ and Nagle and Strickland-Constable. ${ }^{18}$ The present discussion of the research is brief; see Xu et al. ${ }^{1,2}$ and $\mathrm{Xu}$ and Faeth ${ }^{3}$ for additional discussion of soot processes in premixed flames, Xu and Faeth, ${ }^{6}$ Kim et al., ${ }^{7}$ Xu et al., ${ }^{9}$ and El-Leathy et al. ${ }^{10}$ for additional discussion of soot processes in diffusion flames, and $\mathrm{Xu}^{19}$ and El-Leathy ${ }^{20}$ for more detailed descriptions of the experimental methods used during the present investigation.

\section{Experimental Methods}

\section{Test Apparatus}

The present burner was the same as the burner used during several earlier studies of soot processes in diffusion flames; e.g., see $\mathrm{Xu}$ and Faeth, ${ }^{6} \mathrm{Xu}$ et al., ${ }^{9}$ and El-Leathy et al. ${ }^{10}$ The burner had a 34.8-mm-diam inner port, directed vertically upward, for both the acetylene/argon fuel stream of the diffusion flames and the methane/oxygen/nitrogen reactant mixture stream of a premixed flame that was used to calibrate the present measurements of the concentrations of $\mathrm{H}, \mathrm{OH}$, and $\mathrm{O}$ radicals. A 60-mm-diam coannular outer port was used both for the oxygen/argon coflow of the diffusion flames and for the nitrogen coflow of the premixed calibration flame. The oxygen/argon coflow of the diffusion flames served to eliminate natural convection instabilities and the penetration of ambient nitrogen into the soot-containing regions, whereas the nitrogen coflow of the premixed calibration flame served to eliminate the annular diffusion flame for this fuel-rich premixed flame to improve the accuracy of the calibration measurements for the radical species concentrations measurements.

\section{Instrumentation}

The present measurements were similar to past work discussed by Xu et al. ${ }^{9}$ and El-Leathy et al. ${ }^{10}$ and will be described only briefly. All measurements of soot and flame structure were confined to the axis of the present flames because this is the soot path, where soot forms at fuel-rich conditions near the cool core of the present diffusion flames and is drawn directly toward and through the flame sheet, similar to paths taken by soot in practical nonpremixed turbulent flames. ${ }^{4}$ The following properties were measured: soot volume fractions, soot and gas temperatures, concentrations of major gas species, soot structure, gas velocities, and the concentrations of some $(\mathrm{H}, \mathrm{OH}$, and O) radical species. Given these properties, soot surface growth and oxidation rates, as well as the properties that are thought to affect these reaction rates, can be found.

Soot and gas temperatures are nearly identical ${ }^{6}$; therefore, soot (gas) temperatures were found by deconvoluting spectral radiation intensities for chordlike paths through the flames. Temperatures were computed based on spectral radiation intensities at six wavelength pairs in the wavelength range $550-830 \mathrm{~nm}$. Temperature differences between the average and any of the line pairs were less than $50-100 \mathrm{~K}$, yielding experimental uncertainties ( $95 \%$ confidence) of these measurements less than $50 \mathrm{~K}$.

Concentrations of major gas species $\left(\mathrm{Ar}, \mathrm{H}_{2} \mathrm{O}, \mathrm{H}_{2}, \mathrm{O}_{2}, \mathrm{CO}, \mathrm{CO}_{2}\right.$, $\mathrm{CH}_{4}, \mathrm{C}_{2} \mathrm{H}_{2}, \mathrm{C}_{2} \mathrm{H}_{4}, \mathrm{C}_{2} \mathrm{H}_{6}, \mathrm{C}_{3} \mathrm{H}_{6}, \mathrm{C}_{3} \mathrm{H}_{8}, \mathrm{C}_{6} \mathrm{H}_{6}$, and $\mathrm{Ne}$ ) were measured by isokinetic sampling and gas chromatography. Note that $\mathrm{C}_{3} \mathrm{H}_{6}, \mathrm{C}_{3} \mathrm{H}_{8}$, and $\mathrm{C}_{6} \mathrm{H}_{6}$ were not found in the present flames, whereas $\mathrm{Ne}$ was a tracer gas added to estimate effects of radial diffusion of the lithium-containing species that were used to find $\mathrm{H}, \mathrm{OH}$, and O concentrations. The gas chromatograph column system was generally the same as for earlier work. ${ }^{-10}$ This was problematical for the present flames, however, because $\mathrm{Ar}$ and $\mathrm{O}_{2}$ cannot be separated using this arrangement. This difficulty was handled by measuring the combined $\mathrm{Ar} / \mathrm{O}_{2}$ chromatograph peak before and after converting the $\mathrm{O}_{2}$ to $\mathrm{CO}_{2}$ in a heated $(870-\mathrm{K})$ column containing activated charcoal and then finding the separate $\mathrm{Ar}$ and $\mathrm{O}_{2}$ concentrations by difference. Experimental uncertainties (95\% confidence) of the major gas species concentration measurements were less than $10 \%$ for stable gas species having concentrations greater than $0.1 \%$, increasing to roughly $30 \%$ at the present limit of detection of stable gas species.

Soot particles observed during the present investigation consisted of aggregates of nearly spherical and monodisperse primary soot particles at every local condition within each flame. Primary soot particle diameters were measured using thermophoretic sampling and analysis by transmission electron microscopy (TEM) and highresolution transmission electron microscopy (HRTEM), effects of soot property biasing due to the sampler passing through other portions of the flames having been determined to be small; see $\mathrm{Xu}$ et al. ${ }^{9}$ and El-Leathy et al. ${ }^{10}$ The experimental uncertainties $(95 \%$ confidence) of primary particle diameters at a given point in the test flames, found from TEM images, are estimated to be less than $10 \%$.

Streamwise gas velocities were measured using laser velocimetry. For these measurements, the fuel stream was seeded with aluminum oxide particles whose nominal diameter was $1 \mu \mathrm{m}$. The experimental uncertainties (95\% confidence) of these measurements were less than $5 \%$.

Finally, measurements of $\mathrm{H}, \mathrm{OH}$, and $\mathrm{O}$ concentrations were carried out by deconvoluted absorption following the $\mathrm{Li} / \mathrm{LiOH}$ atomic absorption technique of Neoh et al., ${ }^{15-17}$ using the laminar premixed flame, mentioned earlier, to calibrate these measurements. The experimental uncertainties (95\% confidence) of these measurements were less than $30 \%$.

\section{Test Conditions}

The present results involve measurements from three test flames having acetylene/argon fuel streams burning in oxygen/argon coflows. The test conditions for these three flames are summarized in Table 1. Similar to past work, dilution of the fuel stream (with argon for the present flames) was used to reduce soot concentrations in the flames; this approach kept maximum soot concentrations smaller than $2 \mathrm{ppm}$ to avoid problems of large soot concentrations for present measurement techniques. Luminous flame lengths (taken to be the extent of yellow luminosity due to the presence of soot) of the test flames were all $60 \mathrm{~mm}$. Stoichiometric flame lengths, based on stoichiometric atomic ratios of $\mathrm{C}$ and $\mathrm{H}$ as the fuel and $\mathrm{O}$ as the oxidant, were determined from the measured species concentrations in the flames. These stoichiometric flame lengths were smaller than the luminous flame lengths for flames 1 and 2, implying the presence of soot surface reactions under both fuel-rich and fuel-lean conditions for these flames; in contrast, luminous and stoichiometric flame lengths were comparable for flame 3 , implying that all soot surface reactions were confined to fuel-rich conditions for this flame. The stoichiometric flame temperatures in Table 1 were found from adiabatic flame temperature calculations using the algorithm of McBride et al. ${ }^{21}$ Finally, the typical acetone impurity concentrations of acetylene, pointed out as a potential problem for flame experiments to study soot processes by Hamins et al. ${ }^{22}$ and Colket et al., ${ }^{23,24}$ are 
not thought to cause any difficulties for the present measurements, based on evaluation of this effect by $\mathrm{Xu}$ and Faeth. ${ }^{6}$

\section{Results and Discussion}

\section{Soot Structure}

Soot particles observed during the present investigation were similar to those seen during earlier studies of soot processes in laminar premixed and diffusion flames; see Refs. 1-10 and references cited therein. Figures 1a-1c are typical TEM photographs, whereas

Table 1 Summary of test laminar jet diffusion flames ${ }^{\mathbf{a}}$

\begin{tabular}{|c|c|c|c|}
\hline \multirow[b]{2}{*}{ Parameter } & \multicolumn{3}{|c|}{ Flame } \\
\hline & 1 & 2 & 3 \\
\hline Acetylene in fuel stream, $\%$ by vol & 12.0 & 12.0 & 12.6 \\
\hline Argon in fuel stream, \% by vol & 88.0 & 88.0 & 87.4 \\
\hline Acetylene flow rate, $\mathrm{cm}^{3} / \mathrm{s}$ & 5.07 & 6.87 & 9.60 \\
\hline Argon flow rate, $\mathrm{cm}^{3} / \mathrm{s}$ & 37.0 & 50.0 & 67.0 \\
\hline Oxygen in burner coflow, $\%$ by vol & 33.6 & 48.8 & 75.4 \\
\hline Argon in burner coflow, $\%$ by vol & 66.4 & 51.2 & 24.6 \\
\hline Oxygen coflow rate, $\mathrm{cm}^{3} / \mathrm{s}$ & 107.0 & 116.0 & 189.0 \\
\hline Argon coflow rate, $\mathrm{cm}^{3} / \mathrm{s}$ & 211.0 & 122.0 & 62.0 \\
\hline Fuel port exit velocity, $\mathrm{mm} / \mathrm{s}$ & 44.2 & 59.8 & 80.5 \\
\hline Coflow port exit velocity, $\mathrm{mm} / \mathrm{s}$ & 169.0 & 127.0 & 134.0 \\
\hline Luminous flame length, mm & 60 & 60 & 60 \\
\hline Stoichiometric flame length, $\mathrm{mm}$ & 48 & 57 & 61 \\
\hline$R e,-^{\mathrm{b}}$ & 115 & 156 & 210 \\
\hline$F r \times 10^{4},{ }^{\mathrm{b}}$ & 57.3 & 104.6 & 190.0 \\
\hline Stoichiometric flame temperature, $\mathrm{K}^{\mathrm{c}}$ & 2667 & 2776 & 2878 \\
\hline
\end{tabular}

${ }^{\mathrm{a}}$ Laminar round-jet diffusion flames with a 34.8-mm-inside-diameter fuel port flowing fuel/argon mixtures and a 60-mm-inside-diameter coflow port flowing oxygen/argon mixtures, ambient temperature of $294 \pm 2 \mathrm{~K}$, and pressure of $98 \pm 1 \mathrm{kPa}$. Gas purities (\% by vol): argon, $99.6 \%$; acetylene, $99.6 \%$; oxygen, $99.6 \%$. Volume flow rates pertain to normal pressure and temperature conditions.

${ }^{\mathrm{b}}$ Nominal value based on mean port exit velocity.

${ }^{\mathrm{c}}$ Adiabatic flame temperature for stoichiometric combustion of the burner flow and coflow at atmospheric pressure.
Figs. 1d-1f are typical HRTEM photographs of soot particles along the axes of the present flames at the point where soot concentrations are a maximum. Images of soot particles at other locations in the present flames, however, were similar. In general, the TEM images indicated that the soot particles consisted of roughly spherical primary soot particles that had nearly constant diameters at a particular flame condition (e.g., the standard deviation of primary particle diameters was less than $10 \%$ ), collected into aggregates that are known to be mass fractal objects. ${ }^{25}$ The mean number of primary particles per aggregate increased with increasing distance from the burner exit up to the point where oxidation caused the aggregates to break apart, near the end of the soot oxidation region; see the measurements of Sunderland et al. ${ }^{4}$ for results directly illustrating this behavior for soot-containing diffusion flames.

The HRTEM images in Figs. 1d-1f also are similar to soot aggregates observed during past studies of soot formation in flames; see El-Leathy et al., ${ }^{10}$ Heckman and Harling, ${ }^{26}$ Lahaye and Prado, ${ }^{27}$ Garo et al., ${ }^{28}$ Hess and Herd, ${ }^{29}$ Ishiguro et al., ${ }^{30}$ Dobbins, ${ }^{31}$ Chen and Dobbins, ${ }^{32}$ and references cited therein for other examples. In general, throughout the soot-containing region, the primary soot particles exhibited an outer shell having a sheetlike structure parallel to the rounded outer surface of the primary soot particles and an irregular inner core that appeared to result from coalescence of several smaller primary soot particles near the soot nucleation condition. (The irregular nature of the inner core is most evident from HRTEM images near the end of soot oxidation where the outer shell has been largely removed by soot surface oxidation; see El-Leathy et al. ${ }^{10}$ for examples of primary soot particles at this condition.)

Finally, primary soot particles observed in all the test flames considered here, e.g., the measurements of Refs. 1-10 and the present investigation, exhibited identical soot surface growth and oxidation properties and consisted of amorphous soot with no evidence of graphitic structures (whose presence is indicated by plane layered structures within primary soot particles; see Lahaye and Prado ${ }^{27}$ and Hess and Herd ${ }^{29}$ for examples of these structures) typical of

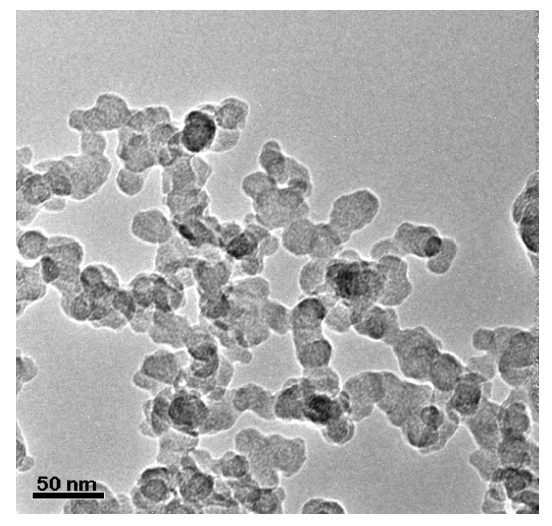

a)

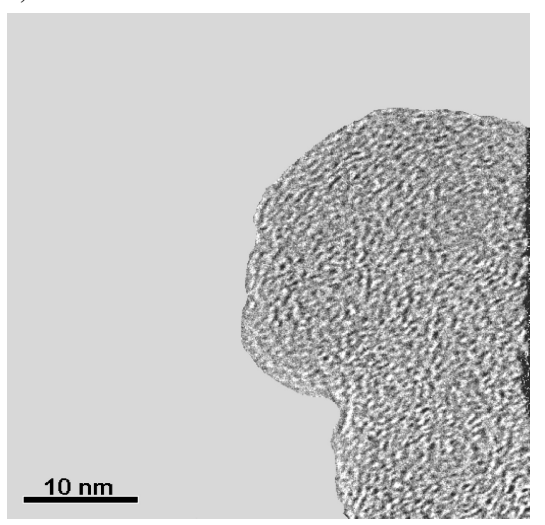

d)

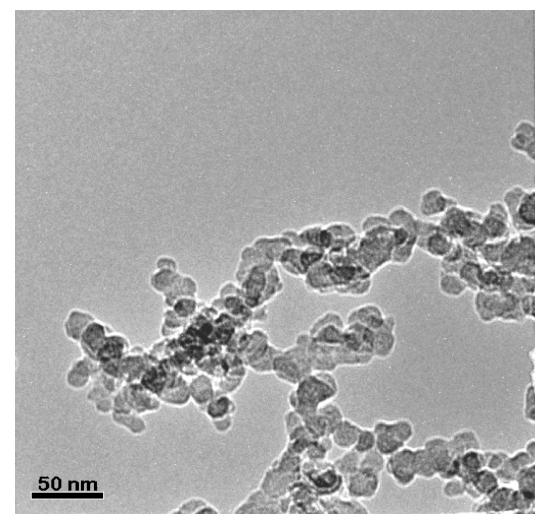

b)

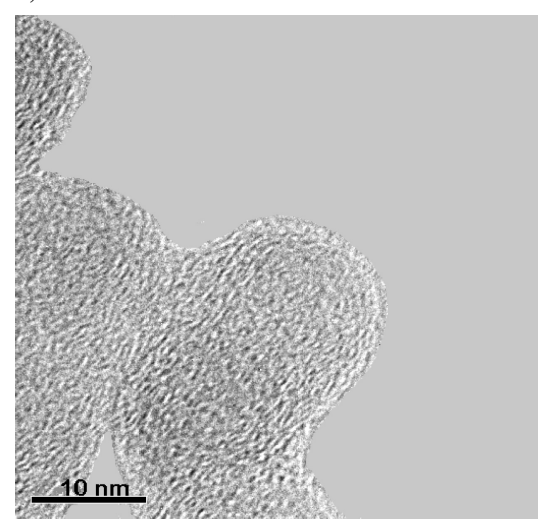

e)

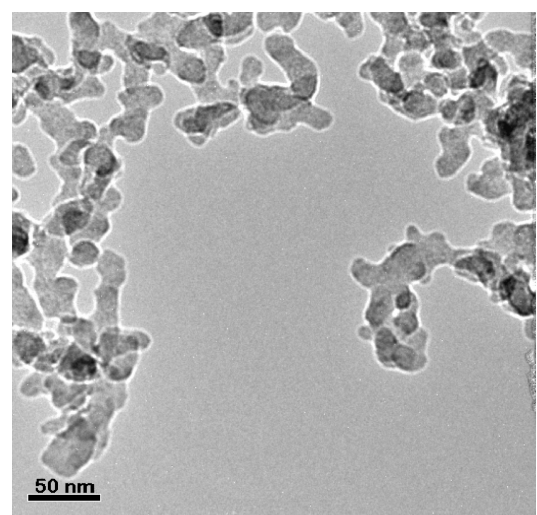

c)

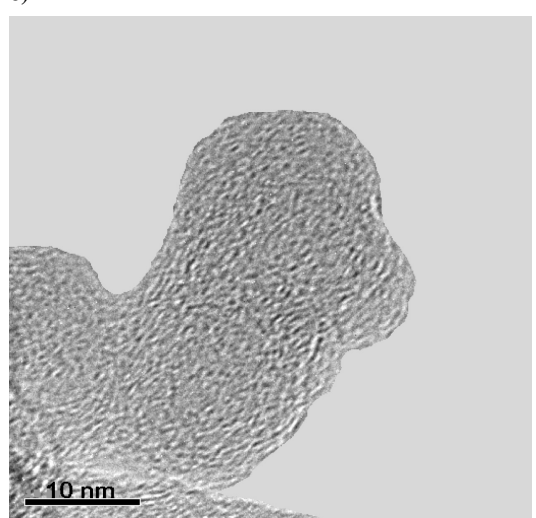

f)

Fig. 1 TEM and HRTEM photographs of soot aggregates at the maximum soot volume fraction location along the axes of the present laminar jet diffusion flames at atmospheric pressure: a-c), TEM photographs of soot aggregates in flames 1, 2, and 3; and d-f), HRTEM photographs of soot aggregates in flames 1-3. 
other observations of the structure of primary soot particles in flame environments. See Refs. 27-30 and references cited therein.

\section{Flame Structure}

Measurements of gas (soot) temperatures, streamwise gas velocities, soot volume fractions, primary soot particle diameters, concentrations of major gas species, and concentrations of radical species $(\mathrm{H}, \mathrm{OH}$, and $\mathrm{O})$ are plotted as a function of height above the burner exit in Figs. 2-4 for flames 1-3, respectively. The right-hand boundaries of these plots correspond to the luminous flame boundary, i.e., the point where yellow luminosity due to continuum radiation from soot disappears, indicating complete consumption of soot particles due to soot oxidation (since no soot was emitted from any of the test flames). The stoichiometric $(\phi=1)$ condition is indicated on the plots for flames 1 and 2; however, this condition roughly corresponds to the right-hand boundary of the plot for flame 3. Elapsed times in the flames, found by integrating the streamwise velocity measurements along the axes of the flames, are indicated at the top of Figs. 2-4. These elapsed times are relative to the first streamwise measuring station where detectable soot volume fractions were observed (32-35 $\mathrm{mm}$ above the jet exit). It is convenient to divide the present flames into two regions separated by the location of the maximum soot concentration condition, as follows: 1) the region upstream of this condition, where soot formation dominates other soot reaction processes and soot concentrations increase with increasing distance from the burner exit, which will be called the soot formation region; and 2) the region downstream of this condition, where soot oxidation dominates other soot reaction processes and soot concentrations decrease with increasing distance from the burner exit, which will be called the soot oxidation region.

Gas (soot) temperatures reach broad maxima near the end of the soot formation region. The temperature ranges in the present flames are as follows: flame 1, 1900-2000 K; flame 2, 2000-2200 K; and flame 3, 2100-2350 K. The maximum temperatures in the present

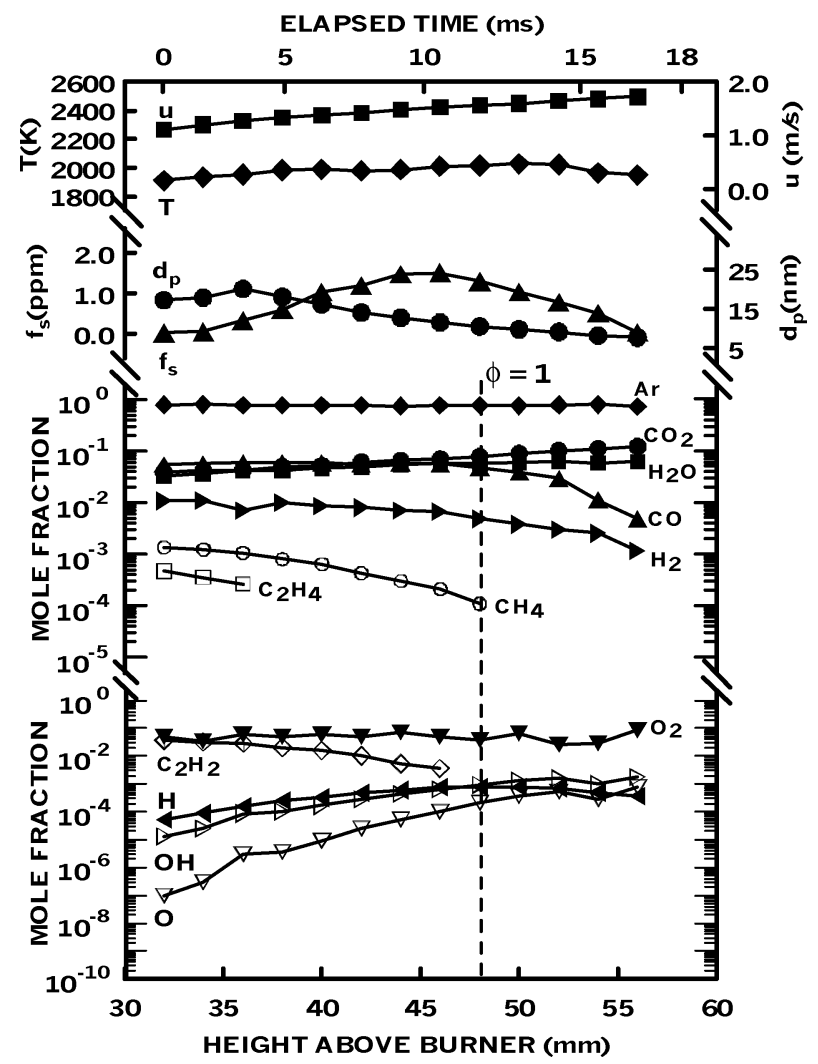

Fig. 2 Measured soot and flame properties along the axis of an acetylene/argon-fueled laminar jet diffusion flame burning in an oxygen/ argon coflow at atmospheric pressure: flame 1, fuel stream of $12.0 \%$ $\mathrm{C}_{2} \mathrm{H}_{2}$ and $88.0 \%$ Ar by volume; oxidant coflow of $33.6 \% \mathrm{O}_{2}$ and $66.4 \%$ Ar by volume.

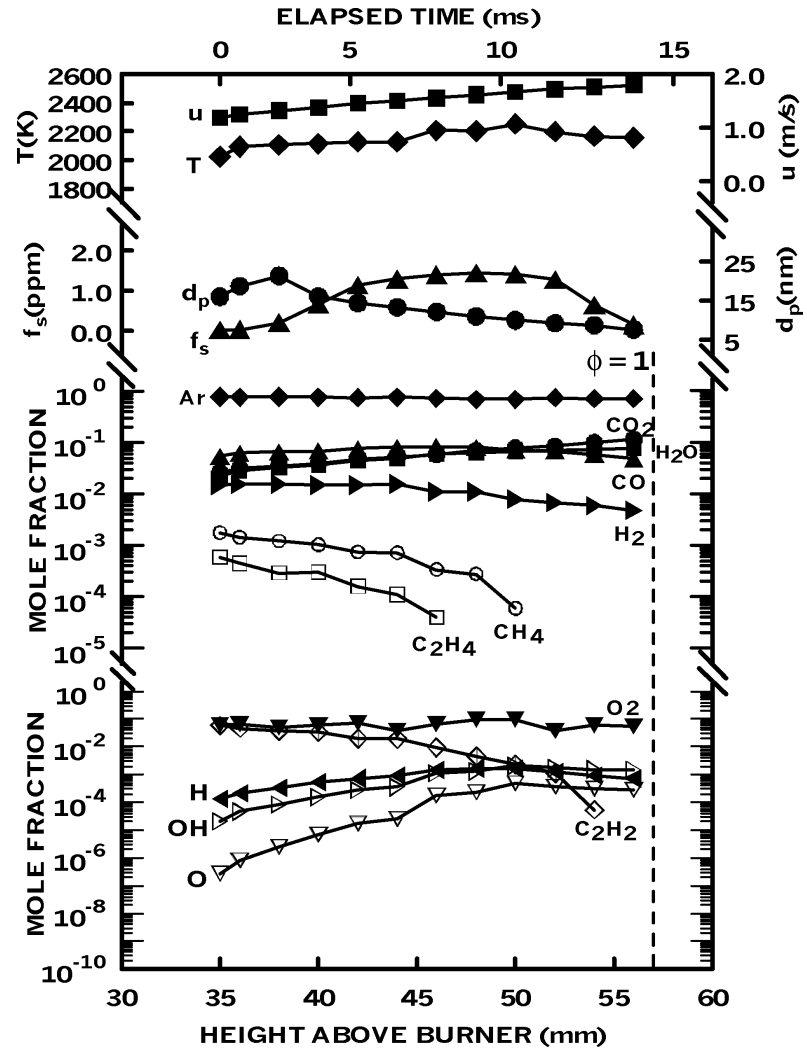

Fig. 3 Measured soot and flame properties along the axis of an acetylene/argon-fueled laminar jet diffusion flame burning in an oxygen/ argon coflow at atmospheric pressure: flame 2, fuel stream of $12.0 \%$ $\mathrm{C}_{2} \mathrm{H}_{2}$ and $88.0 \%$ Ar by volume; oxidant stream of $48.8 \% \mathrm{O}_{2}$ and $51.2 \%$ Ar by volume.

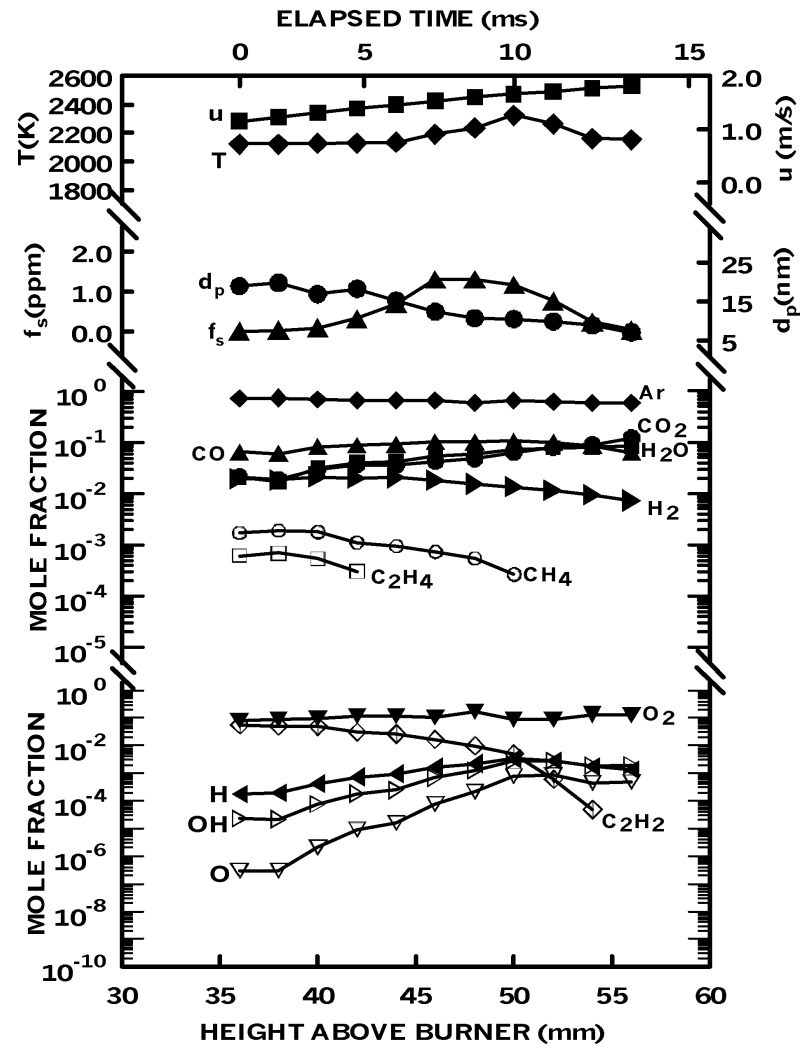

Fig. 4 Measured soot and flame properties along the axis of an acetylene/argon-fueled laminar jet diffusion flame burning in an oxygen/ argon coflow at atmospheric pressure: flame 3, fuel stream of $12.6 \%$ $\mathrm{C}_{2} \mathrm{H}_{2}$ and $87.4 \%$ Ar by volume; oxidant coflow of $75.4 \% \mathrm{O}_{2}$ and $24.6 \%$ Ar by volume. 
flames are considerably reduced from the potential stoichiometric temperatures summarized in Table 1, mainly due to heat losses caused by continuum radiation from soot, as discussed in Xu et al., ${ }^{9}$ El-Leathy et al. ${ }^{10}$ and references cited therein.

Due to effects of buoyancy, velocities in Figs. 2-4 increase from 1 to $2 \mathrm{~m} / \mathrm{s}$ with increasing distance from the burner exit for the range of conditions illustrated in the figures and even more for the range of conditions summarized in Table 1 . This increase of velocities causes a corresponding distortion of the elapsed time scales illustrated at the top of Figs. 2-4.

Primary soot particle diameters reach maximum values relatively early in the soot formation region in Figs. 2-4, which is characteristic of all the laminar diffusion flames considered here; see Refs. 410. However, the same behavior has been observed along the axis of soot-containing diffusion flames by others as well; see Dobbins et al. ${ }^{31,33,34}$ This behavior is caused by accelerating soot primary particle nucleation rates with increasing streamwise distance, which are due to progressively increasing $\mathrm{H}$ concentrations with increasing streamwise distance throughout the soot formation region. As a result, the relatively few primary soot particles formed near the onset of soot formation (at soot inception conditions), which become large due to long periods of soot surface growth in a region where acetylene concentrations are large, are superseded by much larger numbers of primary soot particles formed later in the soot formation region that are smaller due to shorter periods of soot surface growth in regions where the growth rates are reduced due to smaller acetylene concentrations. In particular, numbers of primary soot particles increase by factors in the range 100-10,000 in going from the maximum-primary-particle-diameter condition to the maximum-soot-concentration condition; thus, the few large soot particles formed early in the soot-containing region have little effect on average primary soot particle diameters observed later in the soot formation region, i.e., the standard deviation of primary soot particle diameters remained smaller than $10 \%$ for all flame conditions considered here. This behavior is aided because soot growth remains relatively rapid near soot inception conditions, as noted by Tesner, ${ }^{35,36}$ which allows the few primary particles at this location to grow relatively large.

Soot formation becomes significant when $\mathrm{H}$ concentrations exceed $10 \mathrm{ppm}$ under conditions where acetylene concentrations are relatively large and the end of the soot formation region is reached when acetylene concentrations become small (less than $1 \%$ by volume) in a region where $\mathrm{H}$ concentrations remain relatively large. This behavior is not surprising, however, because past work has shown that soot surface growth dominates the formation of soot in flames and that soot surface growth occurs mainly by the HACA mechanism whose leading reaction rate term is proportional to the product of the acetylene and $\mathrm{H}$ concentrations, $\left[\mathrm{C}_{2} \mathrm{H}_{2}\right][\mathrm{H}] .{ }^{1-10}$

The concentrations of major stable gas species in Figs. $2-4$ are similar to those observed in other laminar diffusion flames that have been studied, e.g., Refs. 4-10. As is typical of flames having acetylene as the fuel, acetylene concentrations progressively decrease with increasing streamwise distance from the burner exit. The final combustion products, $\mathrm{CO}_{2}$ and $\mathrm{H}_{2} \mathrm{O}$, increase with increasing distance from the burner exit throughout the soot-containing region, tending toward maximum values near the flame sheet $(\phi=1)$ condition for the present test flames. Intermediate combustion products associated with water-gas equilibrium, $\mathrm{CO}$ and $\mathrm{H}_{2}$, are present in relatively large concentrations throughout the soot-containing region, with $\mathrm{CO}$ reaching broad maxima just downstream of the soot formation region, whereas $\mathrm{H}_{2}$ decreases continuously with increasing streamwise distance from the burner exit for the range of conditions illustrated in Figs. 2-4. Finally, argon is present in both the fuel- and oxygen-containing streams and tends to remain relatively constant along the axes of the present flames for the conditions illustrated in Figs. 2-4.

Concentrations of species mainly responsible for soot surface oxidation $\left(\mathrm{OH}\right.$ and $\left.\mathrm{O}_{2}\right)$, based on past studies, ${ }^{7,9}$ are significant throughout both the soot formation and oxidation regions; in fact, concentrations of $\mathrm{O}_{2}$ are rather large (roughly $10 \%$ by volume) in the present oxygen-enriched flames, which were used to provide high-temperature soot-containing flames. As a result, soot surface growth and oxidation proceed at the same time and gross soot surface growth rates must be corrected for effects of soot oxidation in order to accurately evaluate mechanisms of soot surface growth. In addition, the fact that substantial rates of soot formation can occur in the presence of high $\mathrm{O}_{2}$ concentrations provides further evidence of the relatively low rates of soot oxidation by $\mathrm{O}_{2}$ in diffusion flame environments that has been observed during earlier studies; see Refs. 7 and 9. Similarly, concentrations of species known to be responsible for soot surface growth $\left(\mathrm{C}_{2} \mathrm{H}_{2}\right.$ and $\left.\mathrm{H}\right)$, based on past studies, ${ }^{1-10}$ are significant throughout both the soot formation and oxidation regions; as a result, soot surface oxidation and growth proceed at the same time and gross soot surface oxidation rates must also be corrected for effects of soot surface growth.

Computed superequilibrium ratios of $\mathrm{H}, \mathrm{OH}$, and $\mathrm{O}$ and fuelequivalence ratios along the axes of the three test flames are illustrated in Fig. 5. The superequilibrium ratios were found from the temperatures and compositions measured in the flames, given the equilibrium constant data of Chase et al. ${ }^{37}$ Present methods of finding radical concentrations involve the assumption of partial equilibrium among $\mathrm{H}, \mathrm{OH}$, and $\mathrm{O}$; the superequilibrium ratios of $\mathrm{H}$ and $\mathrm{OH}$ are identical as a result. Superequilibrium ratios of $\mathrm{H}$ and $\mathrm{OH}$ generally are smaller in the present diffusion flames, which involved temperatures higher than $2000 \mathrm{~K}$ in the soot-containing region, than in the diffusion flames studied earlier, which involved temperatures lower than $2000 \mathrm{~K}$ in the soot-containing region. Thus superequilibrium ratios of $\mathrm{H}$ and $\mathrm{OH}$ are roughly 0.5 near soot inception conditions, increasing to values of 4-10 as the end of the soot-containing region is approached. The superequilibrium range is larger for $\mathrm{O}$, with values near 0.1 at soot inception and 5-75 near the end of the soot-containing region. Thus, the availability of relatively large concentrations of $\mathrm{H}$ through most of the soot-containing region helps promote the HACA soot surface growth mechanism proposed by

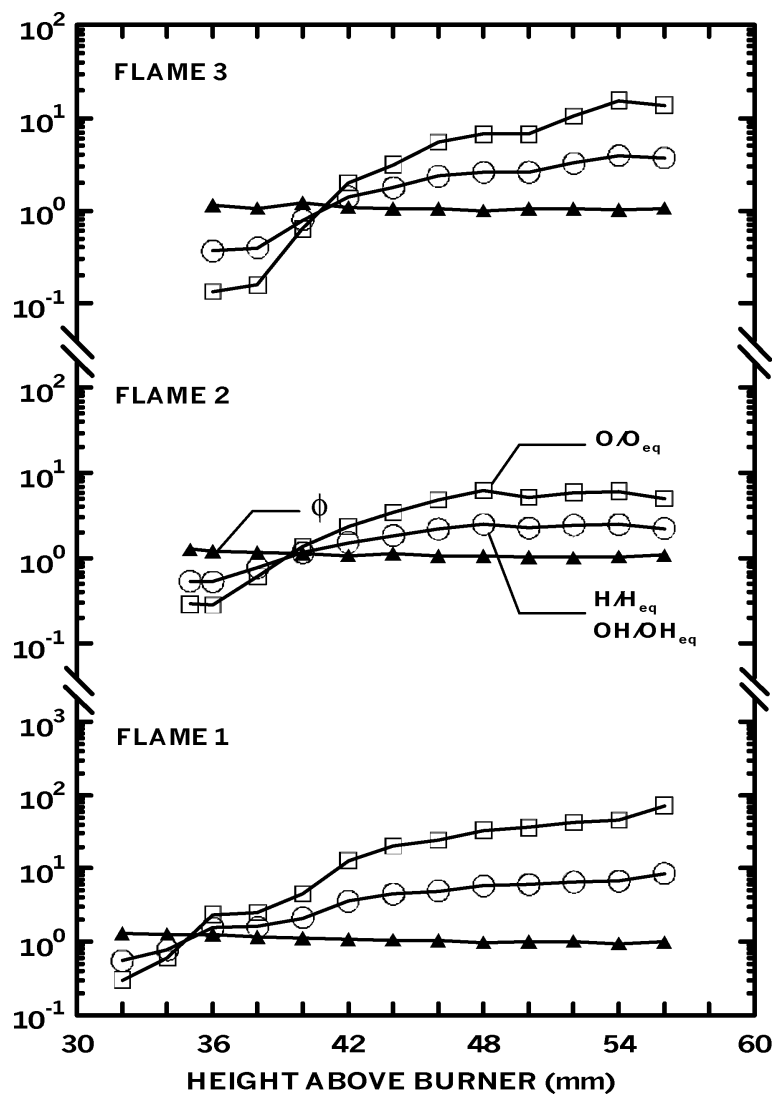

Fig. 5 Measured $\mathrm{H}, \mathrm{OH}$, and $\mathrm{O}$ superequilibrium ratios and fuelequivalence ratios along the axes of the present round acetylene/argonfueled laminar jet diffusion flames burning in oxygen/argon coflows at atmospheric pressure. 
Colket and Hall, ${ }^{11}$ Frenklach and Wang, ${ }^{12,13}$ and Kazakov et al., ${ }^{14}$ whereas the relatively large concentrations of $\mathrm{OH}$ help promote the $\mathrm{OH}$ soot surface oxidation mechanism proposed by Neoh et al. ${ }^{15-17}$ In contrast, $\mathrm{O}$, much like other potential oxidizing species, except $\mathrm{OH}$, is not a significant soot oxidizer in spite of its large superequilibrium ratios.

\section{Soot Surface Growth Rates}

Major assumptions used to find gross soot surface growth rates were identical to earlier work, ${ }^{1-10}$ as follows: 1) soot mass production is dominated by soot surface growth rather than by soot particle nucleation; 2) effects of diffusion (Brownian motion) and thermophoresis on soot motion are small, so that soot particles convect along the axes of the flames at the local gas velocity; 3) the density of soot is constant (taken to be $1850 \mathrm{~kg} / \mathrm{m}^{3}$ from Ref. 4); 4) the surface area available for soot surface growth is equivalent to constant-diameter spherical primary soot particles that meet at a point. The justification of these assumptions and the detailed methods of finding soot surface growth rates are described in Refs. 4 and 6 and will not be repeated here. The experimental uncertainties ( $95 \%$ confidence) of the present soot surface growth rates are estimated to be smaller than $30 \%$.

Soot surface growth and oxidation proceed at the same time; therefore, gross soot surface growth rates must be corrected for effects of soot surface oxidation. This was done during the present study using the $\mathrm{OH} / \mathrm{O}_{2}$ soot surface oxidation mechanism of Neoh et al. ${ }^{15-17}$ as established for laminar diffusion flame environments by Kim et al. ${ }^{7}$ and $\mathrm{Xu}$ et al. ${ }^{9}$ These results involve a collision efficiency for soot surface oxidation of 0.13 with an uncertainty $(95 \%$ confidence) of 0.04 , with rates of direct soot surface oxidation by $\mathrm{O}_{2}$ taken from Nagle and Strickland-Constable ${ }^{18}$ representing a relatively small parallel soot oxidation channel. Notably, these results agree within experimental uncertainties with the soot surface oxidation results found by Neoh et al. ${ }^{15-17}$ in premixed flames, as well as with the results found during the present investigation for hightemperature diffusion flames. To be conservative about potential effects of soot surface oxidation, however, determinations of soot surface growth rates corrected for effects of soot surface oxidation were limited to conditions where estimated soot surface oxidation rates never exceeded half the gross soot surface growth rates, similarly to past work, e.g., Refs. 1-6. It should be noted, however, that this procedure mainly identified conditions where soot surface growth dominated soot surface oxidation and that corrections of soot surface growth rates for effects of soot surface oxidation were all small for the measurements reported here. Finally, use of the present $\mathrm{OH} / \mathrm{O}_{2}$ soot surface oxidation mechanism yielded essentially the same net soot surface growth rates as the earlier approximate approach used in Refs. $1-6$ based on a $\mathrm{CO}_{2} / \mathrm{H}_{2} \mathrm{O} / \mathrm{O}_{2}$ soot surface oxidation mechanism.

Net soot surface growth rates were interpreted using the HACA mechanisms of Colket and Hall, ${ }^{11}$ Frenklach and Wang, ${ }^{12,13}$ and Kazakov et al. ${ }^{14}$ to maintain consistency with earlier evaluations of these mechanisms based on results in some laminar premixed flames ${ }^{1-3}$ and laminar diffusion flames having temperatures smaller than $2000 \mathrm{~K}$ (Refs. 6, 7, and 10). In all cases, the net soot surface growth rates, corrected for effects of soot surface oxidation, were expressed as follows:

$$
w_{g}=\alpha_{i} R_{i}
$$

where $i=\mathrm{CH}$ or FW for the HACA soot surface growth rate mechanisms of Colket and Hall ${ }^{11}$ and Frenklach and Wang ${ }^{12,13}$ and Kazakov et al. ${ }^{14}$ respectively. The $R_{i}$ were found from the measurements. The parameters $\alpha_{i}$ are empirical steric factors on the order of unity, with $\alpha_{\mathrm{CH}}$ specified to be a constant, ${ }^{11}$ and $\alpha_{\mathrm{FW}}$ specified to be a function of temperature. ${ }^{12-14}$ The details of these mechanisms, the formulas for the $R_{i}$, and the reaction rate parameters used in computing values of the $R_{i}$ can be found in Xu et al. ${ }^{1}$ An exception to the description of Xu et al., ${ }^{1}$ however, was that the Colket and Hall ${ }^{11}$ mechanism was modified based on the study of soot surface growth at pressures of 0.1-1.0 atm due to Kim et al. ${ }^{7}$ In particular, Kim et al. ${ }^{7}$ found that reaction 3 of this mechanism, e.g.,

$$
\mathrm{C}_{\mathrm{s}} \cdot \rightarrow \mathrm{C}_{2} \mathrm{H}_{2}+\text { products }
$$

where $C_{s}$ - represents a radical site on the surface of a primary soot particle, caused the overall Colket and Hall ${ }^{11}$ mechanism to yield a poor correlation of the measurements at small pressures. To correct this difficulty, reaction 3 was deleted from the Colket and Hall ${ }^{11}$ mechanism as discussed by Kim et al., ${ }^{7}$ which resulted in a smaller best-fit value of the constant steric factor, $\alpha_{\mathrm{CH}}$, than found during earlier work (e.g., Refs. 1, 2, 6, and 7) as discussed later. In contrast, the mechanism of Frenklach and Wang ${ }^{12,13}$ and Kazakov et al ${ }^{14}$ and the nature of the correlation for the steric factor, $\alpha_{\mathrm{FW}}$, as a function of temperature were unchanged from earlier work. ${ }^{1-6}$

As a first approximation for all the premixed and diffusion flames considered during the present study, the $R_{i}$ are proportional to the product $[\mathrm{H}]\left[\mathrm{C}_{2} \mathrm{H}_{2}\right]$. Thus, in order to provide a direct test of the HACA soot surface growth mechanism without uncertainties associated with specific mechanisms, values of $w_{g} /\left[\mathrm{C}_{2} \mathrm{H}_{2}\right]$ are plotted as a function of $[\mathrm{H}]$ in Fig. 6.

Measurements illustrated in Fig. 6 include the laminar premixed flames of $\mathrm{Xu}$ et al. ${ }^{1,2}$ and the laminar diffusion flames of $\mathrm{Xu}$ and Faeth, ${ }^{6}$ Kim et al., ${ }^{7}$ El-Leathy et al. ${ }^{10}$ and the present investigation. Taken together, these results involve both premixed and diffusion flame conditions, a variety of hydrocarbons $\left(\mathrm{CH}_{4}, \mathrm{C}_{2} \mathrm{H}_{2}\right.$, $\mathrm{C}_{2} \mathrm{H}_{4}, \mathrm{C}_{3} \mathrm{H}_{6}, \mathrm{C}_{3} \mathrm{H}_{8}$, and $\mathrm{C}_{6} \mathrm{H}_{6}$ ), pressures of 0.1-1.0 atm, and flame temperatures within the soot-containing regions of flames at 1400$2350 \mathrm{~K}$. The results for premixed and diffusion flames in Fig. 6 are distinguished by denoting them as open and either crossed or solid symbols, respectively. An empirical correlation of the measurements is also illustrated in Fig. 6, as follows:

$$
w_{g}=k_{H}[\mathrm{H}]\left[\mathrm{C}_{2} \mathrm{H}_{2}\right]
$$

where $k_{H}=2.85 \times 10^{7} \mathrm{~kg} \mathrm{~m}^{4} /\left(\mathrm{kgmol}^{2} \mathrm{~s}\right)$ with an experimental uncertainty (95\% confidence) of $12 \%$ based on all the measurements illustrated in Fig. 6. This correlation is remarkably good in spite of its simplicity and provides rather strong evidence of the importance of the HACA mechanism for soot surface growth, with $\mathrm{H}$ and $\mathrm{C}_{2} \mathrm{H}_{2}$ being the dominant reactants participating in soot surface growth in flame environments.

A more direct evaluation of the HACA mechanism of soot surface growth is obtained by plotting $w_{g}$ directly as a function of $\alpha_{\mathrm{CH}} R_{\mathrm{CH}}$ for the mechanism of Colket and Hall ${ }^{11}$ (after correlating $\alpha_{\mathrm{CH}}$ as a best-fit constant) and as a function of $\alpha_{\mathrm{FW}} R_{\mathrm{FW}}$ for the mechanism

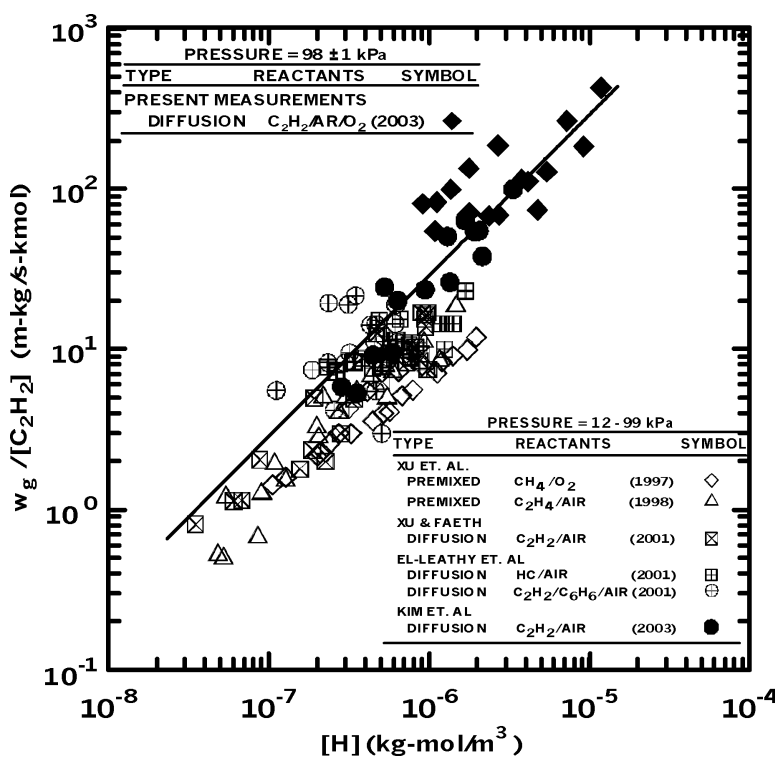

Fig. 6 Soot surface growth rates (corrected for soot surface oxidation) as a function of acetylene and $\mathrm{H}$ concentrations for laminar flames at pressures of 0.1-1.0 atm. 


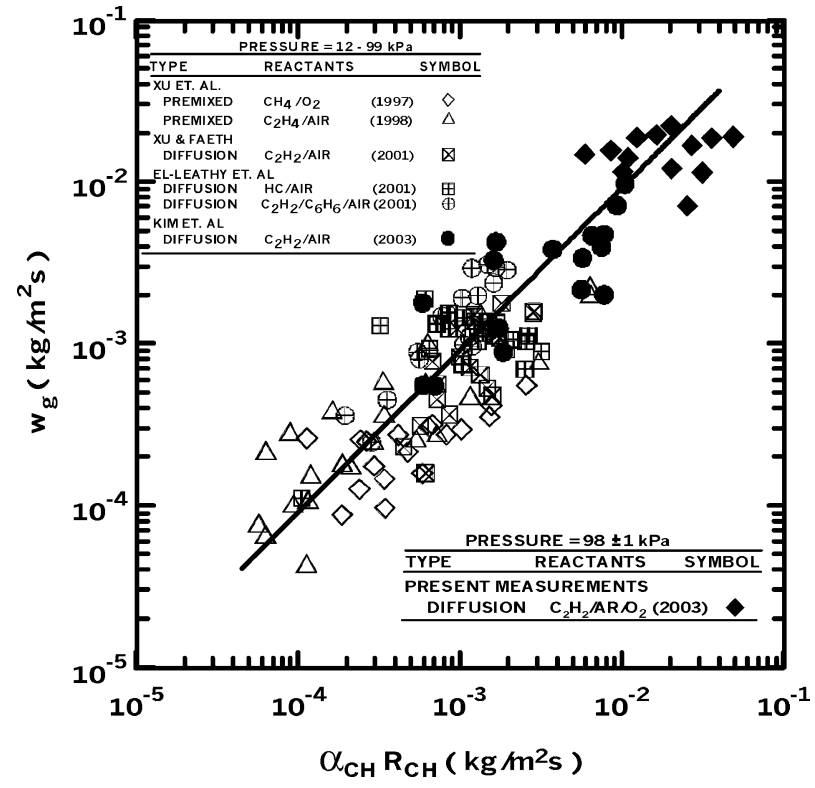

Fig. 7 Soot surface growth rates (corrected for soot surface oxidation) in terms of the HACA mechanism of Colket and Hall ${ }^{11}$ for laminar flames at pressures of 0.1-1.0 atm.

of Frenklach and Wang ${ }^{12,13}$ and Kazakov et al. ${ }^{14}$ (after correlating $\alpha_{\mathrm{FW}}$ as a best-fit function of temperature). Results of this type for the Colket and Hall ${ }^{11}$ mechanism are illustrated in Fig. 7 assuming the same flame conditions as Fig. 6, e.g., the measurements of Refs. 1, 2, 6, 7, and 10 and the present investigation. The best-fit value of the constant steric, $\alpha_{\mathrm{CH}}$, was unchanged from the recent determination of Kim et al. ${ }^{7}$ for flames having temperatures lower than $2000 \mathrm{~K}$, also after deleting reaction 3, namely, $\alpha_{\mathrm{CH}}=0.35$ with an uncertainty ( $95 \%$ confidence) of 0.04 . It is encouraging that this steric factor remains constant as flame temperatures are increased to the range 2000-2350 K and over the range of flame types (premixed or diffusion), fuel types, and pressures mentioned earlier.

The mechanism of Frenklach and Wang ${ }^{12,13}$ and Kazakov et al. ${ }^{14}$ was unaffected by pressure and remains unchanged from earlier evaluations of Refs. 1,2, and 6. The correlation of $\alpha_{\mathrm{FW}}$ as a function of temperature for the complete data base of laminar premixed and diffusion flames was essentially the same as the earlier results in diffusion flames of Xu and Faeth. ${ }^{6}$ The correlation of all the soot surface growth rate data considered here, assuming that $\alpha_{\mathrm{FW}}(T)$ could be represented by an Arhennius function similar to Xu and Faeth, ${ }^{6}$ yielded

$$
\alpha_{\mathrm{FW}}(T)=0.0017 \exp (12100 / T)
$$

with $T(\mathrm{~K})$ and the corresponding plot of $w_{g}$ as a function of $\alpha_{\mathrm{FW}} R_{\mathrm{FW}}$ was qualitatively similar to the plot illustrated by $\mathrm{Xu}$ and Faeth. ${ }^{6}$ This provides a satisfactory correlation with the mechanism of Frenklach and Wang ${ }^{12,13}$ and Kazakov et al. ${ }^{14}$ over the experimental range defined earlier, with values of $\alpha_{\mathrm{FW}}$ on the order of unity and the negative activation energy implied by Eq. (3) corresponding to behavior anticipated by Frenklach and Wang ${ }^{12,13}$ and Kazakov et al. ${ }^{14}$

\section{Soot Surface Oxidation Rates}

The present measurements of soot surface oxidation rates were corrected for effects of soot surface growth rates based on the Colket and Hall ${ }^{11}$ soot surface growth mechanism, as just discussed. No condition was considered, however, where the correction for soot surface growth rate was more than half the gross soot surface oxidation rate. As mentioned earlier, this procedure was used mainly to identify conditions where effects of soot surface oxidation were dominant compared with soot surface growth and that corrections of soot surface oxidation rates for soot surface growth were small for all measurements of soot surface oxidation rates reported here. Another limitation of the evaluation of soot surface oxidation rate mechanisms was that no condition was considered where more than $75 \%$ of the maximum soot mass had been oxidized. This was done to avoid the complications of porous soot surfaces and internal oxidation of primary soot particles observed by Neoh et al. ${ }^{17}$ toward the last stages of soot primary particle oxidation.

The present soot surface oxidation rates (corrected for soot surface growth) were converted into collision efficiencies based on kinetic theory estimates of the collision rates of a given gas species with the surface of primary soot particles, following Neoh et al.: ${ }^{15}$

$$
\eta_{i}=4 w_{\mathrm{ox}} /\left(C_{i}[i] \bar{v}_{i}\right)
$$

where $C_{i}$ is the mass of carbon removed from the surface per mole of species $i$ reacting at the surface, $[i]$ is the gas phase concentration of $i$ adjacent to the surface, and

$$
\bar{v}_{i}=\left(8 R_{u} T /\left(\pi M_{i}\right)\right)^{\frac{1}{2}}
$$

is the Boltzmann equilibrium mean molecular velocity of species $i$. Values of $\eta_{i}$ were measured for several species potentially responsible for soot surface oxidation, assuming $i=\mathrm{O}_{2}, \mathrm{CO}_{2}, \mathrm{H}_{2} \mathrm{O}$, O, and $\mathrm{OH}$.

The collision efficiencies of $\mathrm{O}_{2}$ for soot surface oxidation are plotted as a function of height above the burner in Fig. 8. Results shown in this and the next figure are as follows: values observed for premixed flames at atmospheric pressure by Neoh et al., ${ }^{15}$ values observed for diffusion flames fueled with a variety of hydrocarbons at atmospheric pressure due to $\mathrm{Xu}$ et al., ${ }^{9}$ values observed for acetylene-fueled diffusion flames at pressures of 0.1-1.0 atm due to Kim et al., ${ }^{7}$ values observed for acetylene-fueled diffusion flames at temperatures higher than the rest (2000-2350 K) during the present investigation, and values estimated from the predictions of Nagle and Strickland-Constable ${ }^{18}$ for conditions within the diffusion flames. The Nagle and Strickland-Constable ${ }^{18}$ correlation is widely recognized to be effective for estimating soot surface oxidation rates due to $\mathrm{O}_{2}$, and there are significant concentrations of $\mathrm{O}_{2}$ for soot paths along the axes of the diffusion flames considered in Fig. 8; see Figs. 2-4 and similar flame structure plots in Refs. 6-10. Thus, the fact that the Nagle and Strickland-Constable ${ }^{18}$ estimates of $\mathrm{O}_{2}$ collision efficiencies are 10-100 times smaller than the measurements in diffusion flames suggests that some other species is responsible for soot surface oxidation in diffusion flames. The large scatter of the $\mathrm{O}_{2}$ collision efficiencies in both the diffusion and the premixed flames also supports this conclusion.

The collision efficiencies of $\mathrm{CO}_{2}, \mathrm{H}_{2} \mathrm{O}$, and $\mathrm{O}$ yielded conclusions similar to those just observed for $\mathrm{O}_{2}$; therefore, it is unlikely that

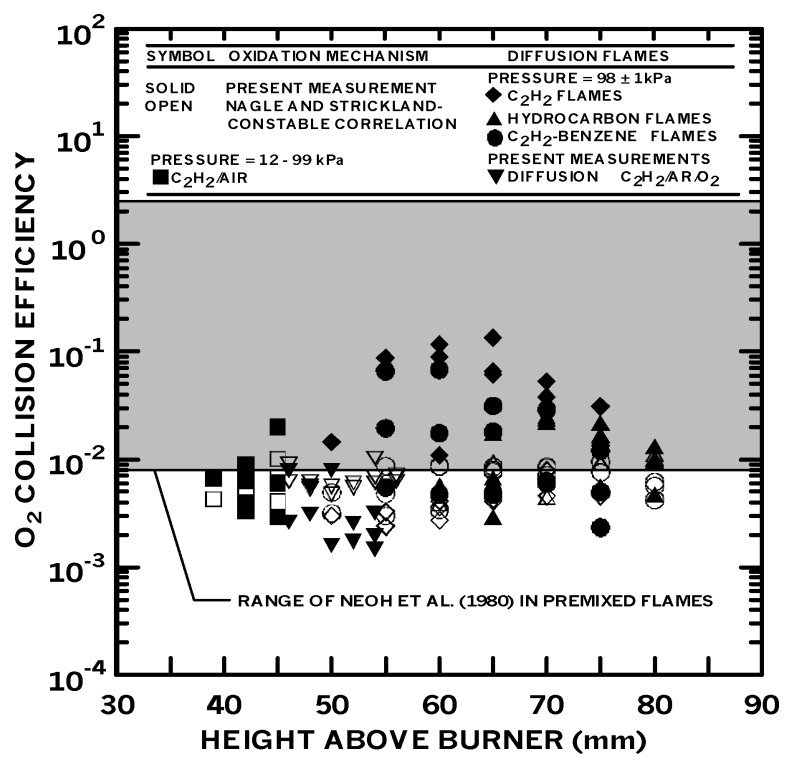

Fig. 8 Collision efficiencies assuming soot surface oxidation (corrected for soot surface growth) due to attack by $\mathrm{O}_{2}$ as a function of distance from the burner exit for laminar flames at pressures of 0.1-1.0 atm. 


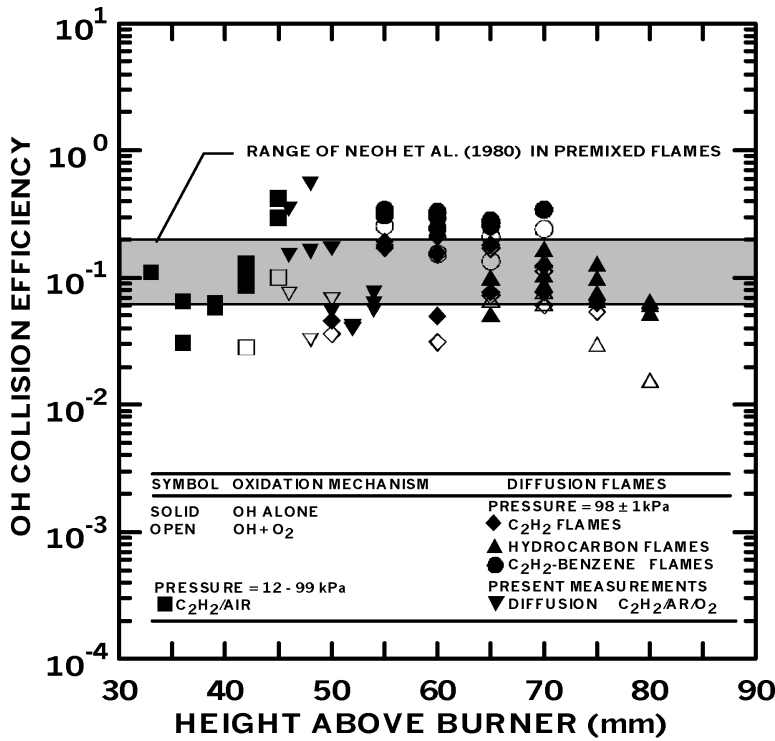

Fig. 9 Collision efficiencies assuming soot surface oxidation (corrected for soot surface growth) due to attack by $\mathrm{OH}$ as a function of distance from the burner exit for laminar flames at pressures of 0.1-1.0 atm.

these species are major contributors to soot surface oxidation in flame environments.

Finally, the collision efficiencies of $\mathrm{OH}$ for soot surface oxidation are plotted as a function of height above the burner in Fig. 9. With a few exceptions, under low-temperature conditions toward the end of soot oxidation (where the development of particle porosity and the internal oxidation of primary soot particles might be a factor), direct $\mathrm{O}_{2}$ surface oxidation of soot is not very important for these conditions, similarly to the results illustrated in Fig. 8. On the other hand, similarly to the observations of Neoh et al., ${ }^{15}$ collision efficiencies of $\mathrm{OH}$ for the diffusion flames exhibit relatively small degrees of scatter and are in excellent agreement with the results of Neoh et al. ${ }^{15}$ for premixed flames. The results for the diffusion flames yield a collision efficiency of 0.13 with an uncertainty $(95 \%$ confidence) of 0.03 , which is in good agreement with the value of 0.13 found by Neoh et al. ${ }^{15}$ for premixed flames using the same treatment of soot structure as the present investigation.

\section{Conclusions}

Flame structure and soot surface growth and oxidation rates were studied for coflowing laminar jet diffusion flames, emphasizing new measurements at higher temperatures in the soot-containing region $(2000-2350 \mathrm{~K})$ than considered before. Exploiting these and earlier measurements, mechanisms of soot surface growth and oxidation were evaluated for a variety of hydrocarbon fuels (methane, acetylene, ethylene, propylene, propane, and benzene), at pressures of 0.1-1.0 atm, at temperatures within the soot-containing region of $1400-2350 \mathrm{~K}$, in both laminar premixed and diffusion flames. The main conclusions of the study are as follows:

1) Soot surface growth rates (corrected for effects of soot surface oxidation) in various laminar flame environments agree within experimental uncertainties and are correlated reasonably well by the HACA soot surface growth rate mechanisms of Colket and Hall ${ }^{11}$ (after a minor correction to delete their reaction 3) and Frenklach and Wang ${ }^{12,13}$ and Kazakov et al., ${ }^{14}$ with steric factors in both these mechanisms having values on the order of unity, as expected.

2) Soot surface oxidation rates (corrected for effects of soot surface growth) in various laminar diffusion flame environments could be correlated reasonably well by assuming a constant collision efficiency for $\mathrm{OH}$ of 0.13 with an uncertainty (95\% confidence) of 0.03 . This finding is in good agreement with the classical work of Neoh et al. ${ }^{15}$ based on measurements in laminar premixed flames at atmospheric pressure. The correction of these results for soot surface oxidation by $\mathrm{O}_{2}$, estimated using the results of Nagle and Strickland-Constable, ${ }^{18}$ was less than $10 \%$, suggesting that soot ox- idation by $\mathrm{OH}$ is a dominant feature of the soot-containing laminar flames considered during the studies of Refs. 6-10 and the present investigation.

Additional study of both soot surface growth and oxidation is needed, however, to resolve effects of pressures greater than atmospheric pressure and effects of hydrocarbons, particularly aromatic hydrocarbons and PAH, other than those considered here. Finally, late soot oxidation after $75 \%$ of the maximum mass of the primary soot particles has been oxidized, when the particles become porous, and internal particle oxidation becomes a factor, also merits consideration to resolve effects of soot oxidation within primary soot particles on total oxidation rates.

\section{Acknowledgments}

This research was supported by NASA Grants NAG3-1245, 1878, and 2048 under the technical management of D. L. Urban and Z.-G. Yuan of NASA John H. Glenn Research Center at Lewis Field.

\section{References}

${ }^{1}$ Xu, F., Sunderland, P. B., and Faeth, G. M., "Soot Formation in Laminar Premixed Ethylene/Air Flames at Atmospheric Pressure," Combustion and Flame, Vol. 108, No. 4, 1997, pp. 471-493.

${ }^{2}$ Xu, F., Lin, K.-C., and Faeth, G. M., "Soot Formation in Laminar Premixed Methane/Oxygen Flames at Atmospheric Pressure," Combustion and Flame, Vol. 115, Nos. 1/2, 1998, pp. 195-209.

${ }^{3}$ Xu, F., and Faeth, G. M., "Structure of the Soot Growth Region of Laminar Premixed Methane/Oxygen Flames," Combustion and Flame, Vol. 121, No. 4, 2000, pp. 640-650.

${ }^{4}$ Sunderland, P. B., Köylü, Ü.Ö., and Faeth, G. M., "Soot Formation in Weakly-Buoyant Acetylene-Fueled Laminar Jet Diffusion Flames Burning in Air," Combustion and Flame, Vol. 100, Nos. 1/2, 1995, pp. 310-322.

${ }^{5}$ Lin, K.-C., Sunderland, P. B., and Faeth, G. M., "Soot Nucleation and Growth in Acetylene/Air Laminar Coflowing Jet Diffusion Flames," Combustion and Flame, Vol. 104, No. 3, 1996, pp. 369-375.

${ }^{6} \mathrm{Xu}, \mathrm{F}$., and Faeth, G. M., "Soot Formation in Laminar Acetylene/Air Diffusion Flames at Atmospheric Pressure," Combustion and Flame, Vol. 125, Nos. 1/2, 2001, pp. 804-819.

${ }^{7}$ Kim, C. H., El-Leathy, A. M., Xu, F., and Faeth, G. M., "Soot Surface Growth and Oxidation in Laminar Diffusion Flames at Pressures of 0.1-1.0 atm," Combustion and Flame, Vol. 136, Nos. 1/2, 2004, pp. 191-207.

${ }^{8}$ Sunderland, P. B., and Faeth, G. M., "Soot Formation in Hydrocarbon/Air Laminar Jet Diffusion Flames," Combustion and Flame, Vol. 105, Nos. 1/2, 1996, pp. 132-146.

${ }^{9}$ Xu, F., El-Leathy, A. M., Kim, C.-H., and Faeth, G. M., "Soot Surface Oxidation in Laminar Hydrocarbon/Air Diffusion Flames at Atmospheric Pressure," Combustion and Flame, Vol. 132, No. 1, 2003, pp. 43-57.

${ }^{10}$ El-Leathy, A. M., Xu, F., Kim, C. H., and Faeth, G. M., "Soot Surface Growth in Laminar Hydrocarbon/Air Diffusion Flames," AIAA Journal, Vol. 41, No. 5, 2003, pp. 856-865.

${ }^{11}$ Colket, M. B., and Hall, R. J., "Successes and Uncertainties in Modeling Soot Formation in Laminar Premixed Flames," Soot Formation in Combustion, edited by H. Bockhorn, Springer-Verlag, Berlin, 1994, pp. 442-470.

${ }^{12}$ Frenklach, M., and Wang, H. "Detailed Modeling of Soot Particle Nucleation and Growth," Proceedings of the Combustion Institute, Vol. 23, 1990, pp. 1559-1566.

${ }^{13}$ Frenklach, M., and Wang, H., Soot Formation in Combustion, edited by H. Bockhorn, Springer-Verlag, Berlin, 1994, pp. 165-192.

${ }^{14}$ Kazakov, A., Wang, H., and Frenklach, M., "Detailed Modeling of Soot Formation in Laminar Premixed Ethylene Flames at a Pressure of 10 Bar," Combustion and Flame, Vol. 110, Nos. 1/2, 1995, pp. 111-120.

${ }^{15}$ Neoh, K. G., Howard, J. B., and Sarofim, A. F., "Soot Oxidation in Flames,"Particulate Carbon, edited by D. C. Siegla and B. W. Smith, Plenum, New York, 1980, pp. 261-277.

${ }^{16}$ Neoh, K. G., "Soot Burnout in Flames," Ph.D. Dissertation, Chemical Engineering Dept., Massachusetts Inst. of Technology, Cambridge, MA, June 1980

${ }^{17}$ Neoh, K. G., Howard, J. B., and Sarofim, A. F., "Effect of Oxidation on the Physical Structure of Soot," Proceedings of the Combustion Institute, Vol. 20, 1984, pp. 951-957.

${ }^{18}$ Nagle, J., and Strickland-Constable, R. F., "Oxidation of Carbon Between 1000-2000 ${ }^{\circ}$," Proceedings of Fifth Carbon Conference, Vol. 1, 1962 , pp. $154-164$.

${ }^{19}$ Xu, F., "Soot Growth in Laminar Premixed Flames," Ph.D. Dissertation, Dept. of Aerospace Engineering, Univ. of Michigan, Ann Arbor, MI, June 1999.

${ }^{20}$ El-Leathy, A. M., "Effects of Fuel Type on the Mechanisms of Soot Formation and Oxidation in Laminar Diffusion Flames," Ph.D. Dissertation, Mechanical Power Dept., Helwan Univ., Cairo, April 2002. 
${ }^{21}$ McBride, B. J., Reno, M. A., and Gordon, A. S., "CET93 and CETPC: An Interim Updated Version of the NASA Lewis Computer Program for Calculating Complex Chemical Equilibrium with Applications," NASA TM 4557, 1994.

${ }^{22}$ Hamins, A., Gordon, A. S., Saito, K., and Seshadri, K., "Acetone Impurity in Acetylene from Tanks," Combustion Science and Technology, Vol. 45, Nos. 5 and 6, 1986, pp. 309-310.

${ }^{23}$ Colket, M. B, III, Seery, D. J., and Palmer, H. B., "The Pyrolysis of Acetylene Initiated by Acetone," Combustion and Flame, Vol. 75, Nos. 3 and 4, 1989, pp. 343-366.

${ }^{24}$ Colket, M. B, III, Seery, D. J., and Palmer, H. B., "On Impurity Effects in Acetylene Pyrolysis," Combustion and Flame, Vol. 84, Nos. 3 and 4, 1991, pp. 434-437.

${ }^{25}$ Köylü, Ü.Ö., Faeth, G. M., Farias, T. L., and Carvalho, M. G., "Fractal and Projected Structure Properties of Soot Aggregates," Combustion and Flame, Vol. 100, No. 4, 1995, pp. 621-633.

${ }^{26}$ Heckman, F. A., and Harling, D. F., "Progressive Oxidation of Selected Particles of Carbon Blacks: Further Evidence for a New Microstructural Model,"Rubber Chemical Technology, Vol. 39, 1966, pp. 1-13.

${ }^{27}$ Lahaye, J., and Prado, G., "Morphology and Internal Structure of Soot and Carbon Blacks," Particulate Carbon, edited by D. C. Siegla and G. W. Smith, Plenum, New York, 1981, pp. 33-55.

${ }^{28}$ Garo, A., Lahaye, J., and Prado, G., "Mechanisms of Formation and Destruction of Soot Particles in a Laminar Methane-Air Diffusion Flame," Proceedings of the Combustion Institute, Vol. 21, 1986, pp. 1023-1031.

${ }^{29}$ Hess, W. M., and Herd, C. R., "Microstructure, Morphology and General Physical Properties," Carbon Black, edited by J.-B. Donoret, R. C. Bonsal, and M.-J. Wang, Marcel Dekker, New York, 1993, pp. 89-173.

${ }^{30}$ Ishiguro, T., Takatori, Y., and Akihama, K., "Microstructure of Diesel
Soot Particles Probed by Electron Microscopy: First Observations of Inner Core and Outer Shell," Combustion and Flame, Vol. 108, Nos. 1/2, 1997, pp. 231-234.

${ }^{31}$ Dobbins, R. A., "The Early Soot Particle Formation in Hydrocarbon Flames,"Physical and Chemical Aspects of Combustion, edited by F. L. Dryer and R. F. Sawyer, Gordon and Breach, Amsterdam, 1997, pp. 107-133.

${ }^{32}$ Chen, H. X., and Dobbins, R. A., "Crystallogenesis of Particles Formed in Hydrocarbon Combustion," Combustion Science and Technology, Vol. 159, 2000, pp. 109-128.

${ }^{33}$ Dobbins, R. A., Govatzidakis, G. J., Lu, W., Schwartzman, A. F., and Fletcher, R. A., "Carbonization Rate of Soot Precursor Particles," Combustion Science and Technology, Vol. 121, 1996, pp. 103-121.

${ }^{34}$ Dobbins, R. A., Fletcher, R. A., and Chang, H.-C., "The Evolution of Soot Precursor Particles in a Diffusion Flame," Combustion and Flame, Vol. 115, 1998, pp. 285-298.

${ }^{35}$ Tesner, P. A., "Formation of Dispersed Carbon by Thermal Decomposition of Hydrocarbons," Proceedings of the Combustion Institute, Vol. 7, 1958, pp. 546-553.

${ }^{36}$ Tesner, P. A., "Dispersed Carbon Formation by Acetylene SelfCombustion," Proceedings of the Combustion Institute, Vol. 8, 1960, pp. 627-633.

${ }^{37}$ Chase, M. W., Jr., Davies, C. A., Downey, J. R., Jr., Frurip, D. I., McDonald, R. A., and Syverud, A. M., JANAF Thermochemical Tables, 3rd ed., Journal of Physical Chemistry Reference Data, Vol. 14, Supplement No. 1, 1986, p. 1211.

C. Kaplan Associate Editor 